
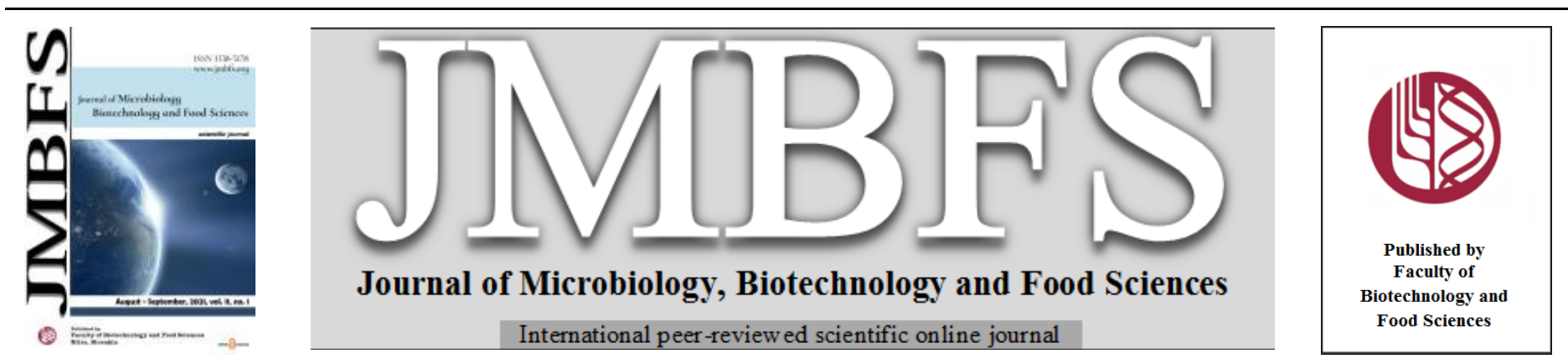

\title{
CHARACTERIZATION OF YEASTS ISOLATED FROM DIFFERENT SOURCES AS PROBIOTICS
}

\author{
Nandakumar Arumugam $^{* 1}$ and Dhivyadharshini Govindharaj ${ }^{2}$
}

\author{
Address(es): \\ ${ }^{1}$ Assistant Professor, Department of Biotechnology, Vel Tech Rangarajan Dr.Sagunthala R\&D Institute of Science and Technology - 600062, Tamilnadu, India, Phone \\ number: +91-7845659621. \\ ${ }^{2}$ B.Tech-Biotechnology, Karpagam Academy of Higher Education, Coimbatore - 641021, Tamil Nadu, India.
}

*Corresponding author: mavericknandy@gmail.com

https://doi.org/10.15414/jmbfs.937

\section{ARTICLE INFO}

Received 3. 10. 2018

Revised 4. 3. 2021

Accepted 24. 3. 2021

Published 1. 8. 2021

$\frac{\overline{\text { Regular article }}}{{ }_{\text {OPEN }} O_{\text {ACCESS }}}$

\begin{abstract}
Probiotics are living microorganisms which are similar to beneficial microorganisms found in the human gut. These microorganisms can be taken as dietary supplements or as food products provides positive effect to the host. In the present study, soil, milk and curd samples were used as source for the isolation of probiotic yeast. The isolates were checked for the probiotic properties such as antimicrobical production, $\mathrm{pH} \&$ temperature tolerance, $\mathrm{NaCl}$ tolerance, cell adhesion, bile tolerance and cholesterol removal. Initially, twelve yeasts were isolated from each of the three different sources and characterization tests were performed. Among the 12 isolates, $\mathrm{M}_{1}$ showed maximum activity in all characterization tests and the conditions optimized are temperature $\left(35^{\circ} \mathrm{C}\right), \mathrm{pH}(3 \& 7)$ and salt tolerance $(5 \%$ of $\mathrm{NaCl}$ ) for the growth of the probiotics. It can be used as a major food supplements and also with high nutritive value for human.
\end{abstract}

Keywords: Probiotics, Yeast, Antibiotic Resistance, Cell Adhesion and Extracellular Polysaccharides

\section{INTRODUCTION}

Probiotics are given to human in sufficient amount to provide health benefits to the host system (Basavaraju and Jamil, 2014). Our digestive tract consists of variety of microbial species that have a symbiotic relationship with the host (Ragavan and Das, 2017; Sridevi et al., 2015). Most commonly used probiotic microbes are bacteria and yeast (Hamed and Elattar, 2013; Del Carmen et al., 2011), which performs a significant function in host system by improving immune system, food digestion, production of short-chain fatty acids and essential vitamins, and colonization resistance against infectious agents (Mishra and Sharma, 2014; Guo et al., 2010).

In general, most of the probiotic organisms belong to lactic acid bacteria, they are Gram-positive, catalase- negative and rods shaped with rounded ends. It usually appears in combined form either as short or long chains. They are a nonflagellated, non-motile and non-spore forming organism (Alander et al., 1999). They are used to produce various beneficial compounds such as antimicrobial, lactic acid, hydrogen peroxide and many bacteriocins. Also, have an ability to interact with host microbial flora and need to possess the antagonistic property against infectious agents such as bacterial, viral and fungal agents (Gorbach, 2002).

They help in influencing several aspects of innate and acquired immunity by inducing phagocytosis and $\operatorname{IgA}$ secretion, modifying T-cell responses, enhancing $\mathrm{TH}_{1}$ ( $\mathrm{T}$ Helper) responses and attenuating $\mathrm{TH}_{2}$ responses (Kechagia et al., 2012). Major mechanism of probiotics includes enhancement of epithelial barrier, increased adhesion to the intestinal mucosa, inhibition of pathogenic adhesion, production of antimicrobial substances and immune system modulation (Bermudez-Brito et al., 2012).

Many food products containing probiotics organisms are wide and still growing in markets. Examples of food products with probiotics are dairy based including fermented milk, cheese, yogurts, buttermilk, ice creams and milk powder (Ankita and Jayati, 2015; Arena et al., 2014). Non-dairy food products include soy based products, nutrition bars, cereals and variety of juices (Kechagia et al., 2012; Král et al., 2012; Pundir et al., 2013). The most important properties for the selection of probiotics are non- pathogenic, ability to adhere to gut, acid \& bile tolerance, thermotolerance, Cholesterol removal, GIT tolerance, EPS production, $\mathrm{pH}$ resistance, production of antimicrobial substance and resistance to antibiotics (Basavaraju and Jamil, 2014; Mishra and Sharma, 2014; Qvirist et al., 2016). Also, it has the ability to survive in the digestive tract and colonize in lumen and colon for long period of time. Additionally, it should be safe for human consumption and should not cause any harmful toxic compounds that affect the human health (Collado et al., 2007).

The advantage of using yeast as probiotic food supplements because of its eukaryotic nature and has the ability to change post-translational modification This makes them to express various therapeutic proteins with proper conformation. Also helps in maintaining microbial flora in gut, prevent proliferation of infectious agents, improves food digestion, production of shortchain fatty acids and essential vitamins (Mishra and Sharma, 2014; Klaenhammer and Kullen, 1999). The main aim of the present study is to isolate and characterize yeast as probiotics from different sources.

\section{MATERIALS AND METHODS}

\section{Isolation of yeast}

Sample such as soil (food waste dumped site), milk (milk vendor) and curd sample (local market) was collected from Eachanari, Coimbatore, Tamil Nadu, India. The collected samples were serially diluted and directetly plated on YEPD (Yeast peptone dextrose) agar plates and incubated at $37^{\circ} \mathrm{C}$ for $24-48$ hours. An antimicrobial agent chloramphenicol $(100 \mu \mathrm{g} / \mathrm{ml})$ was added to inhibit the growth pf bacteria. After 48 hours of incubation, totally 12 isolates, 4 from each of the three sample were isolated includes $\mathrm{S}_{1}-\mathrm{S}_{4}, \mathrm{M}_{1}-\mathrm{M}_{4} \& \mathrm{C}_{1}-\mathrm{C}_{4}$ and used for further analysis (Basavaraju and Jamil, 2014; Mishra and Sharma, 2014).

\section{Characterisation tests for probiotics}

\section{Antimicrobial production test}

The microbial resistance of yeast isolates were tested against pathogenic cultures; E.coli, Bacillus subtilis, Staphylococcus aureus, Salmonella typhi, Pseudomonas $s p$ and Klebsiella pneumonia. The crude extracts from all the isolates were collected by centrifuging the culture at $10,000 \mathrm{rpm}$ for 10 minutes. Then agar well diffusion method was carried out by swabbing the pathogenic culture on each plate and using gel puncture well was created and the extracts were added After incubation, these plates were analysed for the zone of inhibition. The well containing distilled water was used as the control (Basavaraju and Jamil, 2014; Pundir et al., 2013). 


\section{pH tolerance test}

This test checks the ability of the isolates to grow in the acidic and basic environment by finding the growth of the organism at various $\mathrm{pH}$. The YEPD broth containing selected isolates was adjusted to $\mathrm{pH} 1,2,3,4,5,7,9$ and 11 using $1 \mathrm{~N} \mathrm{HCl}$ and $1 \mathrm{~N} \mathrm{NaOH}$. Then, the samples were incubated at $37^{\circ} \mathrm{C}$ for $24-$ 48 hours. The growth of all the isolates was measured at 600nm (Basavaraju and Jamil, 2014; Pundir et al., 2013).

\section{Thermotolerance test}

In this test, the selected yeast isolates were checked for its ability to withstand at various temperatures. The selected 12 yeast isolates were incubated at various temperatures, i.e., $15,25,35$ and $45^{\circ} \mathrm{C}$ for $24-48$ hours. The growth of the organisms was calculated by measuring the absorbance at $600 \mathrm{~nm}$ (Mishra and Sharma, 2014).

\section{Salt tolerance test}

The salt tolerance ability of the 12 isolates was tested by growing the isolates with $\mathrm{NaCl}$ at different concentrations $(0-10 \%)$ at $37^{\circ} \mathrm{C}$ for $24-48$ hours. The $\mathrm{NaCl}$ tolerance ability of these isolates was analyzed by measuring the absorbance at 600nm (Escamilla-Montes et al., 2015; Hoque et al., 2010; Sieladie et al., 2011).

\section{Cell adhesion test}

The ability of the probiotic isolates to adhere onto the cells were measured by microbial adhesion to solvents (MATS). The cultures were centrifuged and the pellets were suspended in potassium phosphate buffer. Chloroform was used as a solvent and mixed in the ratio of 1:3 to all the cell suspensions and kept for 10 minutes incubation and mixed vigorously. Then, these samples were incubated for 20 minutes at room temperature and OD was taken at $600 \mathrm{~nm}$ (EscamillaMontes et al., 2015). The percentage (\%) of cell adhesion to solvent was calculated by the formula:

$$
\% \text { of cell adhesion }=\frac{\mathbf{A}_{\mathbf{0}}-\mathbf{A}_{\mathbf{1}}}{\mathbf{A}_{\mathbf{0}}} * 100
$$

where $\mathrm{A}_{1}$ is absorbance after incubation and $\mathrm{A}_{0}$ is absorbance reading before incubation with solvent.

\section{Bile tolerance test}

The bile tolerance of the probiotic yeast isolates were analysed in the presence of various concentrations of bile salts $(0-100 \mathrm{ppm})$. After incubation, absorbance was measured at 600nm (Pundir et al., 2013).

\section{Cholestrol removal test}

The cholesterol removal potential of the probiotic isolates were analysed with $1 \%$ bile salt \& $100 \mu \mathrm{g}$ of water-soluble cholestrol and incubated at $37^{\circ} \mathrm{C}$ at different time intervals $(4,8,12,24$ and 48 hours). $5 \mathrm{ml}$ of the sample was taken at each interval and centrifuged at 5000rpm. After centrifugation, the supernatant was collected and absorbance was measured at 600nm (Ragavan and Das, 2017). Assimilation rate of cholesterol was calculated by the formula:

Rate of cholesterol removal $=\underline{\text { Cholesterol conc. } \text { in control }- \text { Cholesterol conc. in sample }} * 100$ Cholesterol conc. in control

\section{RESULTS AND DISCUSSION}

\section{Characterization test}

\section{Antimicrobial production test}

The production of antimicrobial compound against specific pathogenic microorganisms by the yeast isolates were given in Table 2 . The results showed that only strain $\mathrm{C}_{1}$ produced antimicrobial substance against $E$. coli and isolates $\mathrm{M}_{1}, \mathrm{~S}_{1}$ and $\mathrm{C}_{4}$ exhibit antimicrobial activity against Bacillus subtilis. The isolates $\mathrm{M}_{1}, \mathrm{M}_{4}$ and $\mathrm{C}_{4}$ developed resistance for Staphylococcus aureus and $\mathrm{M}_{1}$ strain showed exceptionally good results against Salmonella typhi compared to all the isolates. Similarly, $\mathrm{S}_{2}, \mathrm{M}_{1}$ and $\mathrm{M}_{4}$ were able to grow in presence of Pseudomonas $s p$. and all other isolates were insensitive to grow. Among the 12 isolates, $\mathrm{M}_{1}$ and $\mathrm{M}_{4}$ strain showed good results for Klebsiella pneumoniae.

Table 2 Antimicrobial production test

\begin{tabular}{lllllllllllll}
\hline \multirow{2}{*}{ Name of the pathogens } & \multicolumn{10}{c}{ Name of the isolates } \\
\cline { 2 - 12 } & $\mathbf{S}_{\mathbf{1}}$ & $\mathbf{S}_{\mathbf{2}}$ & $\mathbf{S}_{\mathbf{3}}$ & $\mathbf{S}_{\mathbf{4}}$ & $\mathbf{C}_{\mathbf{1}}$ & $\mathbf{C}_{2}$ & $\mathbf{C}_{\mathbf{3}}$ & $\mathbf{C}_{\mathbf{4}}$ & $\mathbf{M}_{\mathbf{1}}$ & $\mathbf{M}_{\mathbf{2}}$ & $\mathbf{M}_{\mathbf{3}}$ & $\mathbf{M}_{\mathbf{4}}$ \\
\hline E.coli & - & - & - & - & ++ & - & - & - & - & - & - \\
\hline Bacillus subtilis & + & - & - & - & - & - & - & ++ & ++ & - & - & - \\
\hline Staphylococcus aureus & - & - & - & - & - & - & - & + & +++ & - & - & + \\
\hline Salmonanella typhii & - & - & - & - & - & - & - & - & + & - & - & - \\
\hline Pseudomonoas sp & - & + & - & - & - & - & - & - & + & - & - & + \\
\hline Klebsiella pneumoniae & - & - & - & - & - & - & - & - & ++ & - & - & + \\
\hline
\end{tabular}

Legend: + indicates moderate activity of antimicrobical compounds from isolates, ++ indicates good activity of antimicrobical compounds from isolates, +++ indicates excellent activity of antimicrobical compounds from isolates, indicates absence of antimicrobical compounds from isolates.

\section{pH tolerance test}

The effect of different $\mathrm{pH}$ on the growth of 12 isolates was shown in figure 1 From the graph, it was found that most of the selected isolates exhibited maximum tolerant growth at $\mathrm{pH} 3,5$ and 7 , whereas $\mathrm{S}_{3}$ exhibited at $\mathrm{pH} 11$ and $\mathrm{C}_{3}$ at $\mathrm{pH} 9$.

\section{pH tolerance test}

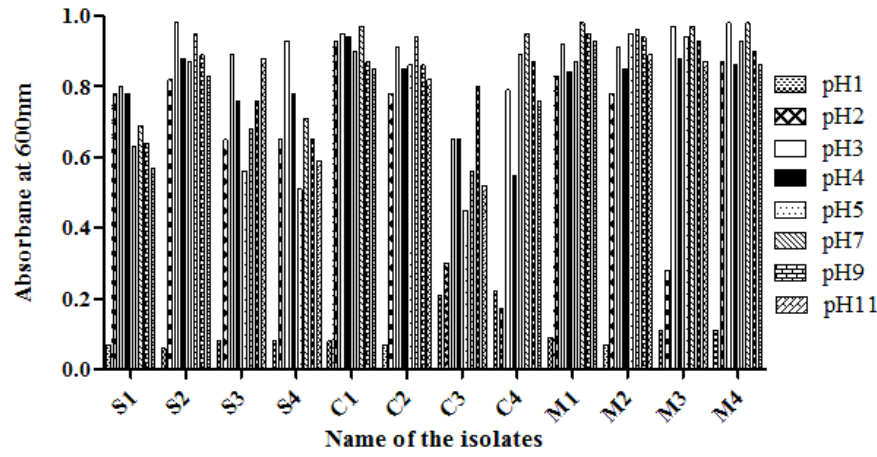

Figure $1 \mathrm{pH}$ Tolerance test for the growth of the probiotic yeast isolates from different sources.
Also, there was an slightly decreased growth at $\mathrm{pH} \mathrm{1,2}$ and 4. From the above results, it was clearly revealed that all the isolates had maximum tolerance at $\mathrm{pH}$ $3 \& 7$ and also growth was observed among the other $\mathrm{pH}$ ranges. During the primary screening, 12 among the 20 yeast isolates showed good growth under acidic condition ( $\mathrm{pH}-2$ ) (Ragavan and Das, 2017).

\section{Thermotolerance test}

The isolated yeast isolates $\mathrm{S}_{1}$ to $\mathrm{S}_{4}, \mathrm{C}_{1}$ to $\mathrm{C}_{4}, \mathrm{M}_{1}$ to $\mathrm{M}_{4}$ was exposed to a different temperature $\left(15^{\circ} \mathrm{C}, 25^{\circ} \mathrm{C}, 35^{\circ} \mathrm{C}, 45^{\circ} \mathrm{C}\right)$ and the results were shown in figure 2. The results confirmed that all stains had maximum growth at $35^{\circ} \mathrm{C}$ except $\mathrm{C}_{3}, \mathrm{M}_{3}$ showed maximum growth at $25^{\circ} \mathrm{C}$. All the isolates were sensitive to grow at $15^{\circ} \mathrm{C}$ and strain $\mathrm{S}_{1}$ exhibited minimum growth at $45^{\circ} \mathrm{C}$.

According to Ragavan and Das, (2017), thermotolerance for 20 yeast isolates conducted from which 12 isolates showed best resistance at $35^{\circ} \mathrm{C}$. All the selected isolates from the study of Sornplang and Piyadeatsoontorn (2016), had an ablity to withstand the temperature in the range of $25,30,37$ and $40^{\circ} \mathrm{C}$. 


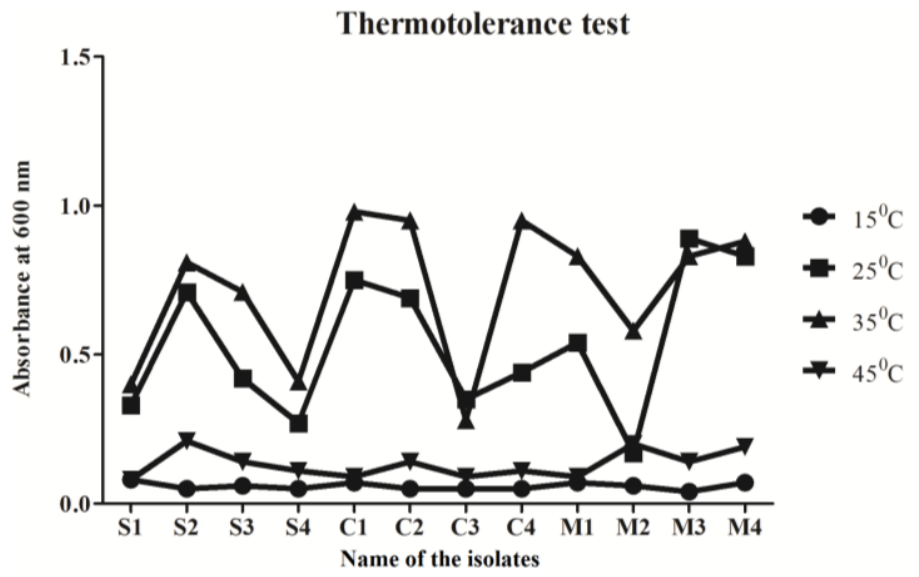

Figure 2 Effect of various temperatures for the growth of the probiotic yeast isolates from different sources.

\section{Salt tolerance test}

For salt tolerance test, the selected isolates $\left(S_{1}\right.$ to $S_{4}, C_{1}$ to $C_{4}, M_{1}$ to $\left.M_{4}\right)$ were incubated in a different concentrations of $\mathrm{NaCl}(2-10 \%)$ in YEPD broth. The growth of the isolates was represented in figure 3. Only isolates $S_{2} \& C_{1}-C_{4}$ has the ability to grow in $\mathrm{NaCl}$ concentration of $2 \%$. Also observed that all the isolates isolated from milk sample $\left(\mathrm{M}_{1}-\mathrm{M}_{4}\right)$ showed increased growth in 2-4\% of $\mathrm{NaCl}$. Except strain $\mathrm{M}_{3}$, all the other isolates of milk sample showed growth in $6 \%$ of $\mathrm{NaCl}$. But the growth was reduced by increasing $\mathrm{NaCl}$ concentration of about $8-10 \%$ for all the isolates.

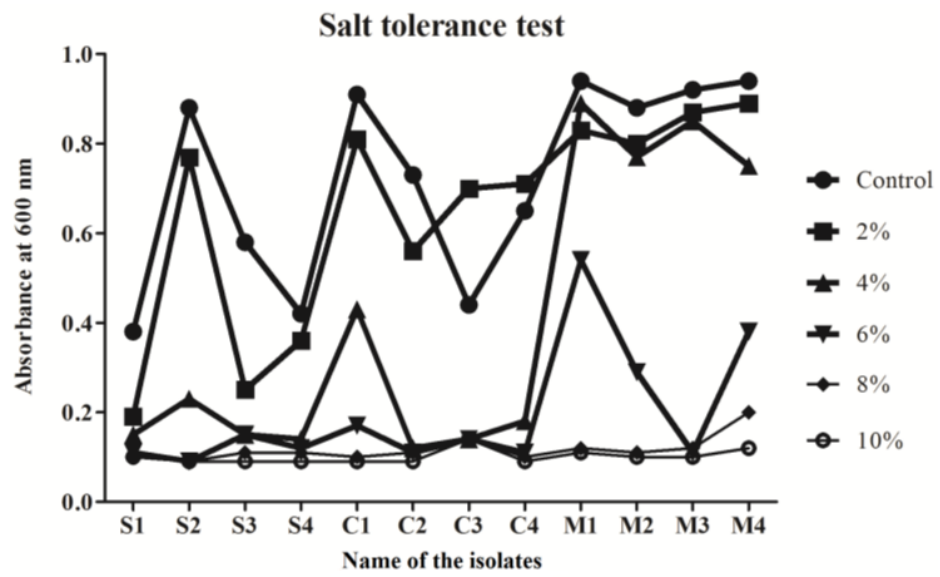

Figure 3 Salt tolerance test for the growth of the probiotic yeast isolates from different sources.

All the isolates that involved in saline tolaerance test had the competence to grow in 0.5 to $9 \% \mathrm{NaCl}$ concentrations (Escamilla-Montes et al., 2015). Similar tes was performed by Ankita and Jayati (2015) and the results from the test showed that most of the selected isolates were able to show resistance in $4 \% \mathrm{NaCl}$.

\section{Cell adhesion test}

The cell adhesion for the selected isolates was measured by cell adhesion hydrophobicity, (i.e) microbial adhesion to solvents (MATS). The percentage of cell adhesion was presented in figure 4 . It was observed that the isolates $S_{1}, M_{1}$, $\mathrm{M}_{2}$ and $\mathrm{M}_{4}$ showed very good adhesion ability of above $50 \%$ i.e., it possess ultrahydrophobic capacity towards the solvent. The hyperhyphobicity level was observed in isolates $\mathrm{S}_{3}, \mathrm{~S}_{4}, \mathrm{C}_{1}$ and $\mathrm{M}_{3}$ showed the adhesion ability between 30 $50 \%$ whereas all other isolates were able to adhere below $30 \%$ (possess hybrophobicity). The adhesion ability was tested with n-Hexadecane and found that most of the selected isolates showed good adhesion ability of about $60 \%$ (Ragavan and Das, 2017).

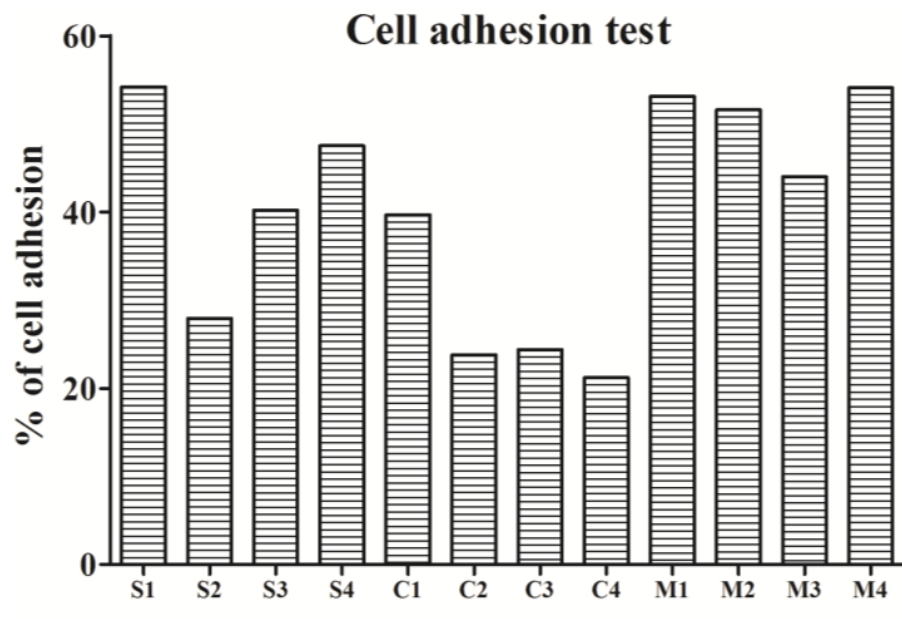

Name of the isolates

Figure 4 Cell adhesion test for the growth of the probiotic yeast isolates from different sources.

\section{Bile tolerance test}

The bile tolerance ability of 12 isolates was revealed in figure 5. From the graph, the bile tolerance ability of the isolates were found to be higher in $25 \mathrm{ppm}$ for the isolates $S_{2}$ to $S_{4}, C_{1}, C_{3}, C_{4}$ and $M_{4}$, whereas $S_{1}$ showed maximum tolerance for $100 \mathrm{ppm}$. The isolates $\mathrm{C}_{2}$ and $\mathrm{M}_{2}$ were able to grow at $75 \mathrm{ppm}$ concentration of bile salt. It was found that other two isolates of milk sample $M_{1}$ and $M_{3}$ showed higher resistance to $50 \mathrm{ppm}$ than other bile concentrations.

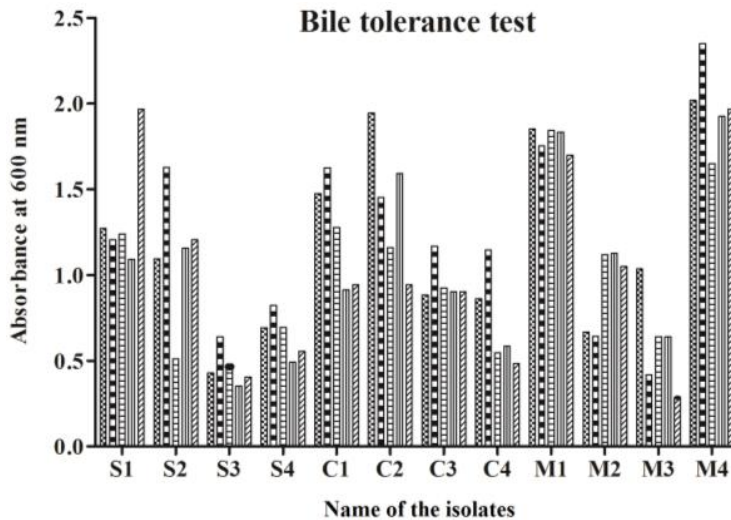

冈ppm

\$ 25ppm

Е 50ppm

एा) $75 \mathrm{ppm}$

บ10 100pm

Figure 5 Bile Tolerance test for the growth of the probiotic yeast isolates from different sources.

Bile tolerance ability carried out by Ragavan and Das (2017), the bile salt concentration of $0.6 \%$ showed maximum growth of the selected isolates. Another work done by Pundir et al., 2013, depicted that the selected isolates were able to tolerate different concentrations of bile salt $(0.5-2 \%)$. The concentrations of bile salt used in the test were $0.05,0.1,0.15$ and $0.3 \%$ and noticed that all isolates were able to multiply in the all concentration (Hoque et al., 2010).

\section{Cholesterol removal test}

The rate of cholesterol removal ability was found at different time intervals $(4,8$, $24,48^{\text {th }}$ hours) and resulted in figure 7 . The result was exhibited that all strains $S$ to $S_{4}, C_{1}$ to $C_{3}, M_{1}$ and $M_{4}$ indicated the increased reduction of cholesterol level from $4^{\text {th }}$ to $48^{\text {th }}$ hour of incubation. Similar results were found in the cholesterol removal test during $24^{\text {th }}$ hour interval (Ragavan and Das, 2017). 


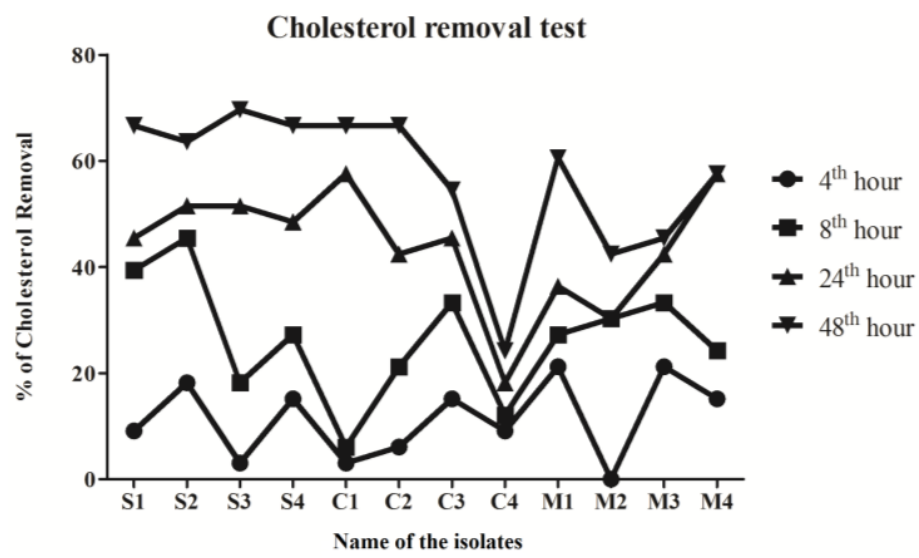

Figure 6 Cholesterol removal test for the growth of the probiotic yeast isolates from different sources.

\section{CONCLUSION}

Thus, the results from the present study it was found that the $\mathbf{M}_{1}$ isolate from the milk sample showed good results against most of the characterization tests and it has an ability to withstand high temperature, $\mathrm{pH}$ and also able to show resistance against most of the microorganisms used by producing antimicrobial compounds compared to other isolates from soil and curd samples. It could be the potential source for the replacement of dietary food intake in the near future.

\section{REFERENCES}

Alander, M., Satokari, R., Korpela, R., Saxelin, M., Vilpponensalmela, T., Mattila-Sandholm, T., \& Von Wright, A. (1999). Persistence of colonisation of human colonic mucosa by a probiotic strain, Lactobacillus rhamnosus GG, after oral consumption. Applied and Environmental Microbiology, 65, 351-354. https://doi.org/10.1128/aem.65.1.351-354.1999

Ankita, C., \& Jayati, B. (2015). Isolation, identification and analysis of probiotic properties of Lactobacillus spp. from selected regional dairy product. International Journal of Current Microbiology and Applied Sciences, 4(6), 621628.

Arena, M.P., Russo, P., Capozzi, V., Lopez, P., Fiocco, D., \& Spano, G. (2014) Probiotic abilities of riboflavin-overproducing isolates: A novel promising application of probiotics. Applied Microbiology and Biotechnology, 98(17), 7569-7581. http://dx.doi.org/10.1007/s00253-014-5837-x

Basavaraju, B., \& Jamil, K. (2014). Identification and characterization of probiotics from new sources. International Journal of Science and Research, 3(6), 837-841.

Bermudez-Brito, M., Plaza-Díaz, J., Muñoz-Quezada, S., Gómez-Llorente, C., \& Gil, A. (2012). Probiotics mechanisms of action. Annals of nutrition \& metabolism, 61(2), 160-74. http://dx.doi.org/10.1159/000342079

Collado, M.C., Meriluoto, J., \& Salminen, S. (2008). Adhesion and aggregation properties of probiotic and pathogen isolates. European Food Research and Technology, 226(5), 1065-1073. http://dx.doi.org/10.1007/s00217-007-0632-x Del Carmen, S., de Moreno de LeBlanc, A., Miyoshi, A., Santos Rocha, C., Azevedo, V., \& LeBlanc, J.G. (2011). Potential application of probiotics in the prevention and treatment of inflammatory bowel diseases. Ulcers, 1-13. http://dx.doi.org/10.1155/2011/841651

Escamilla-Montes, R., Luna-Gonzalez, A., Flores-Miranda, M., Alvarez-Ruiz, P. Fierro-Coronado, J.A., Sanchez-Ortiz, C.A., \& Avila-Leal, J. (2015). Isolation and Characterization of Potential Probiotic Bacteria Suitable for Mollusk Larvae Cultures. The Thai Journal of Veterinary Medicine, 45(1), 11-21.

Gorbach, S.L. (2002). Probiotics in the third millennium. Digestive and liver disease, 2; 2-7. http://dx.doi.org/10.1016/S1590-8658(02)80155-4

Guo, X.H., Kim, J.M., Nam, H.M., Park, S.Y., \& Kim, J.M. (2010). Screening lactic acid bacteria from swine origins for multistrain probiotics based on in vitro functional properties. Anaerobe, 16(4), 321-326. https://doi.org/10.1016/j.anaerobe.2010.03.006

Hamed, E., \& Elattar, A. (2013). Identification and some probiotic potential of lactic acid Bacteria isolated from Egyptian Camels Milk. Life Science Journal, 10(1), 1952-1961.

Hoque, M.Z., Akter, F., Hossain, K.M., Rahman, M.S.M., Billah. M.M., \& Islam, K.M.D. (2010). Isolation, identification and analysis of probiotic properties of Lactobacillus spp. from Selective Regional Yoghurts. World Journal of Dairy \& Food Sciences, 5(1): 39-46.

Kechagia, M., Basoulis, D., Konstantopoulou, S., Dimitriadi D., Gyftopoulou, K., Skarmoutsou, N., \& Maria Fakiri, E. (2012). Health Benefits of Probiotics: A Review, International Scholarly Research Notices Nutrition, 1-7. http://dx.doi.org/10.5402/2013/481651
Klaenhammer, T.R., \& Kullen, M.J. (1999). Selection and design of probiotics. International Journal of Food Microbiology, 50(1), 45-57. http://dx.doi.org/10.1016/S0168-1605(99)00076-8

Král, M., Angelovicova, M., \& Mrazova, L. (2012). Application of probiotics in poultry production. Animal Science and Biotechnologies, 45(1), 55-57.

Mishra, A., \& Sharma, K.P. (2014). Isolation and characterization of probiotic microorganism from fermented dairy products. GERF Bulletin of Biosciences, 5(1), 10-14. http://dx.doi.org/10.22159/ajpcr.2017.v10i4.17067

Pundir, R.K., Rana, S., Kashyap, N., \& Kaur, A. (2013). Probiotic potential of lactic acid bacteria isolated from food samples: an in vitro study. Journal of Applied Pharmaceutical Science, $3 \quad$ (03), 085 093.http://dx.doi.org/10.7324/JAPS.2013.30317

Qvirist, L.A., de Filippo, C., Strati, F., Stefanini, I., Sordo, M., Andlid, T., Felis, G.A., Mattarelli, P., \& Cavalieri, D. (2016). Isolation, Identification and Characterization of Yeasts from Fermented Goat Milk of the Yaghnob Valley in $\begin{array}{llll}\text { Tajikistan. Frontiers in } & \text { Microbiology, } & \text { 7, }\end{array}$ http://dx.doi.org/10.3389/fmicb.2016.01690

Ragavan, M.L., \& Das, N. (2017). Isolation and Characterization of Potential Probiotic Yeasts from Different Sources. Asian Journal of Pharmaceutical and $\begin{array}{llll}\text { Clinical Research, } & 10 & \text { 45), } & \text { 451-455. }\end{array}$ https://doi.org/10.22159/ajpcr.2017.v10i4.17067

Sieladie, D.V., Zambou, N.F., Kaktcham, P.M., Cresci, A., \& Fonteh, F. (2011). Probiotic properties of Lactobacilli isolates isolated from raw cow milk in the western highlands of Cameroon. Innovative Romanian Food Biotechnology, 9 12.

Sornplang, P., \& Piyadeatsoontorn, S. (2016). Probiotic isolates from unconventional sources: A review. Journal of Animal Science and Technology, 58(1), 26. http://dx.doi.org/10.1186/s40781-016-0108-2

Sridevi, V., Sirisha, R., \& Swapna, S.N. (2015). Screening of probiotic Goat Milk and Cow Milk isolates for acid resistance, antagonistic activity and tolerance to antimicrobial activity of Spices: Molecular identification of potential probiotic goat milk isolate, G8. International Journal of Current Microbiology and Applied Sciences, 4(8), 406-421. 